\title{
Cavitation Resistance of Elastomeric Coatings Deposited by Different Methods
}

COSTEL-RELU CIUBOTARIU*, DOINA FRUNZAVERDE*

Center for Research in Hydraulics, Automation and Thermal Processes - CCHAPT, "Eftimie Murgu" University of Resita, 1-4 Traian Sq., 320085 Resita, Romania

In this study a fluid elastomer was applied by two different methods on a martensitic stainless steel substrate, in order to obtain coatings for protection against cavitation. The investigations regarding the resistance to cavitation erosion of the elastomeric coatings were carried out by the indirect vibratory method using the values of the cumulative erosion (material loss) developed during a testing period of 600 minutes with a $20 \mathrm{kHz}$ ultrasonic vibrator at a peak-to-peak amplitude of $50 \mu \mathrm{m}$. The experimental results obtained in the laboratory have been processed statistically. They clearly pointed out that the deposition method significantly influences the cavitation resistance of the elastomer.

Keywords: elastomer, protective coatings, wear, cavitation

Cavitation erosion is a major problem in hydropower plants. This phenomenon that consists in the progressive loss of material from a solid surface, affects the runner blades and adjacent areas of the runner [1]. Cavitation is caused by continuous collapse of numerous bubbles due to localized pressure changes during high velocity flow [1, 4]. If the pressure suddenly falls below the vapors pressure, the tensile stress imposed on the liquid generates cavities, because of the numerous small solid and gaseous cavitation nuclei generally present in a real liquid. The cavities collapse violently when they reach a point of greater pressure. This collapse is accompanied by the sudden flow of liquid, which originates stress pulses that can cause plastic deformation on solid surfaces [2-4].

Because the elastomers are a class of soft materials resistant to high loads that can recover their initial shapes after multiple cycles of large deformations, allowing reversible and repeated variations, their functional characteristics have been investigated for a wide range of industrial applications [5-8]. Depending on the type of system in which elastomeric materials are used, they usually manifest good resistance to tensile stresses and good wear behavior [9-14]. Based on these considerations, this paper focused on the possibilities of preventing or decreasing the effects of cavitation erosion of hydraulic steel components by using protective elastomeric coatings. Furthermore, the authors intended to reveal the influence of the deposition method on the cavitation resistance of the layers.

\section{Experimental part}

Test method

The equipment used for the cavitation tests in the Center for Research in Hydraulics, Automation and Thermal Processes (CCHAPT) of the "Eftimie Murgu" University of Resita is an ultrasonic equipment with piezoelectric converter. For the experimental tests carried out within this study, the indirect vibratory method was used with the specimen fixed and fully immersed in the liquid as shown in figure 1 . The resonance frequency of the oscillator was $20 \pm$ $0.5 \mathrm{kHz}$ and the double (peak-to-peak) amplitude of the vibrating sonotrode was $50 \mu \mathrm{m}$. The test liquid was de-ionized water kept at $25 \pm 1$ degree $\mathrm{C}$ using a cooling system with water and a temperature control device. For each new test specimen, the fluid vessel was cleaned and filled up with fresh liquid. The distance between the vibrating sonotrode and the test specimen was chosen in accordance with the recommendations arising from previous research [15-16]. The test specimens were removed periodically after predetermined time intervals and weighed with a precision balance (five decimal places) after cleaning with acetone and drying in air flow. The experimental results have been expressed by using the values of the cumulative erosion (CE).

\footnotetext{
*email: r.ciubotariu@uem.ro; d.frunzaverde@uem.ro
} 


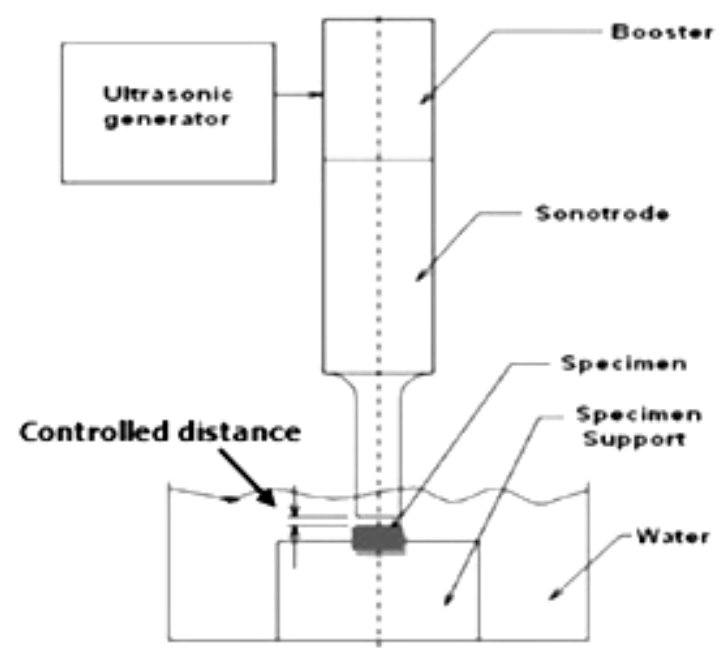

Fig. 1. Schematic representation of the indirect cavitation method [1]

\section{Materials and specimens}

The substrate material for the elastomeric layers was a martensitic stainless steel, as used for the production of runner blades and the adjacent areas of the runner in hydropower plants. After a very thorough blast cleaning of the substrate surface, the fluid elastomer curing at room temperature was applied using two different methods: by brushing and respectively by spraying with a paint gun. Both types of protective layers were tested under the same conditions and the results were processed statistically.

Figure 2 shows the deposited layers in cross section. Both of them have a sponge appearance and are well anchored to the substrate. On the other hand, it can be observed that the sprayed coating is uniform and has a thickness of $1.24 \mathrm{~mm}$, while the thickness of the brushed layer varies between $1.05-1.18 \mathrm{~mm}$.

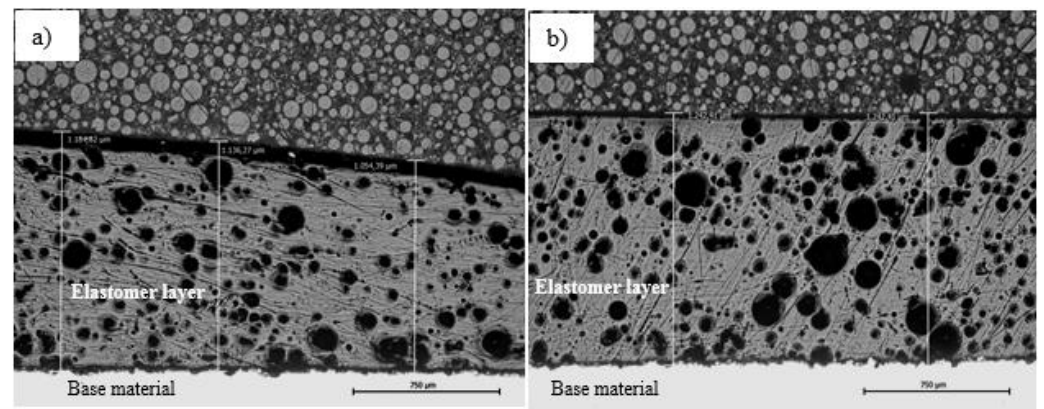

Fig. 2. The thickness of elastomer layers in cross section: a) brushed coating; b) sprayed coating

In table 1 are listed the physical and mechanical properties of the elastomeric material, as specified by the manufacturer. The chemical composition of the substrate material (a martensitic stainless steel), similar to that commonly used for manufacturing of hydro components, is presented in table 2.

Table 1

VALUES FOR PHYSICAL AND MECHANICAL PROPERTIES OF THE ELASTOMER

\begin{tabular}{|l|c|}
\hline Density [g/cm & $1.06-1.09$ \\
\hline $90^{\circ}$ Peel adhesion [N/mm] & 31,52 \\
\hline Tensile strength [MPa] & 15.2 \\
\hline Tear strength [N/mm] & 66.55 \\
\hline High elongation [\%] & 530 \\
\hline Shore A Hardness & 87 \\
\hline
\end{tabular}


Table 2

CHEMICAL COMPOSITION OF THE SUBSTRATE

\begin{tabular}{|c|c|c|c|c|c|c|c|c|}
\hline \multirow{2}{*}{ Material } & \multicolumn{9}{|c|}{ Chemical elements [\%] } \\
\cline { 2 - 9 } & $\mathbf{C}$ & $\mathbf{S i}$ & $\mathbf{M n}$ & $\mathbf{C r}$ & $\mathbf{N i}$ & $\mathbf{M 0}$ & $\mathbf{P}$ & $\mathrm{S}$ \\
\hline Martensitic stainless steel & 0.03 & 0.46 & 0.71 & 12.64 & 3.63 & 0.53 & 0.025 & 0.001 \\
\hline
\end{tabular}

\section{Results and discussions}

In order evaluate the resistance to cavitation erosion of the tested elastomeric coatings applied by the two methods, several specimens were tested for periods of 600 minutes each under the same conditions. The evolution over time of the average value of the total eroded mass $[\Delta \mathrm{m}]$ for three samples tested for every type of layer is represented graphically in figure 3. It is noted that the coating applied by spraying (sample $\mathrm{C} 2$ ) exhibited lower values of the cumulative erosion (CE) in comparison with the layer obtained by brushing (sample C1). Furthermore, the stabilization rate (Vs) of the cavitation erosion for the $\mathrm{C} 2$ coating was about three times lower than that of the $\mathrm{C} 1$ sample. The average values for the $\mathrm{CE}$ and Vs of the tested samples are presented in table 3.

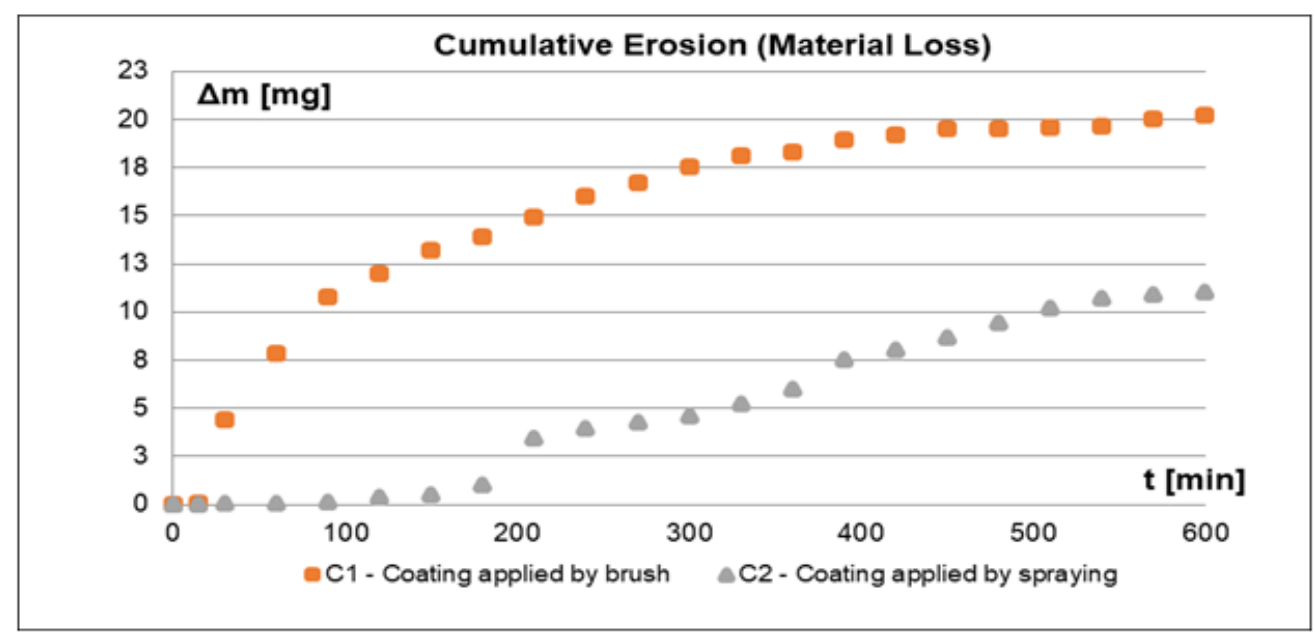

Fig. 3. The average mass variation during the testing period for the elastomeric layers applied by both methods

Table 3

THE AVERAGE VALUES OF THE STABILIZATION RATE, EXPERIMENTAL RESULTS VERSUS STATISTICAL RESULTS

\begin{tabular}{|l|c|c|c|}
\hline Samples & $\mathrm{Vs}\left[\mathrm{mm}^{3} / \mathrm{min}\right] \times 10^{-3}$ & \multicolumn{2}{|c|}{ Experimental } \\
cumulative erosion & $\begin{array}{c}\text { Maximum value } \\
\text { of the estimated error } \\
{[\mathrm{mg}]}\end{array}$ \\
\hline $\mathrm{C} 1$ & 4.2 & 20.23 & 20.47 \\
\hline $\mathrm{C} 2$ & 1.6 & 11.01 & 12.35 \\
\hline
\end{tabular}

As one can observe, beginning from the first minutes of the testing period, the slope of the curve for the $\mathrm{C} 1$ layer increases continuously to minute 450 and then stabilizes, while the curve for the $\mathrm{C} 2$ coating presents an incubation period of about 190. The experimental results represented in figure 3 have been processed statistically in order to determine the dispersion strips (see figure 4) that result from the estimated error and the 2 nd degree polynomial regression curve. These strips were obtained using the average values of the cumulative erosion (material loss) of three samples (S1, S2 and S3) tested for each type of deposition method (C1 and $\mathrm{C} 2$ ). 

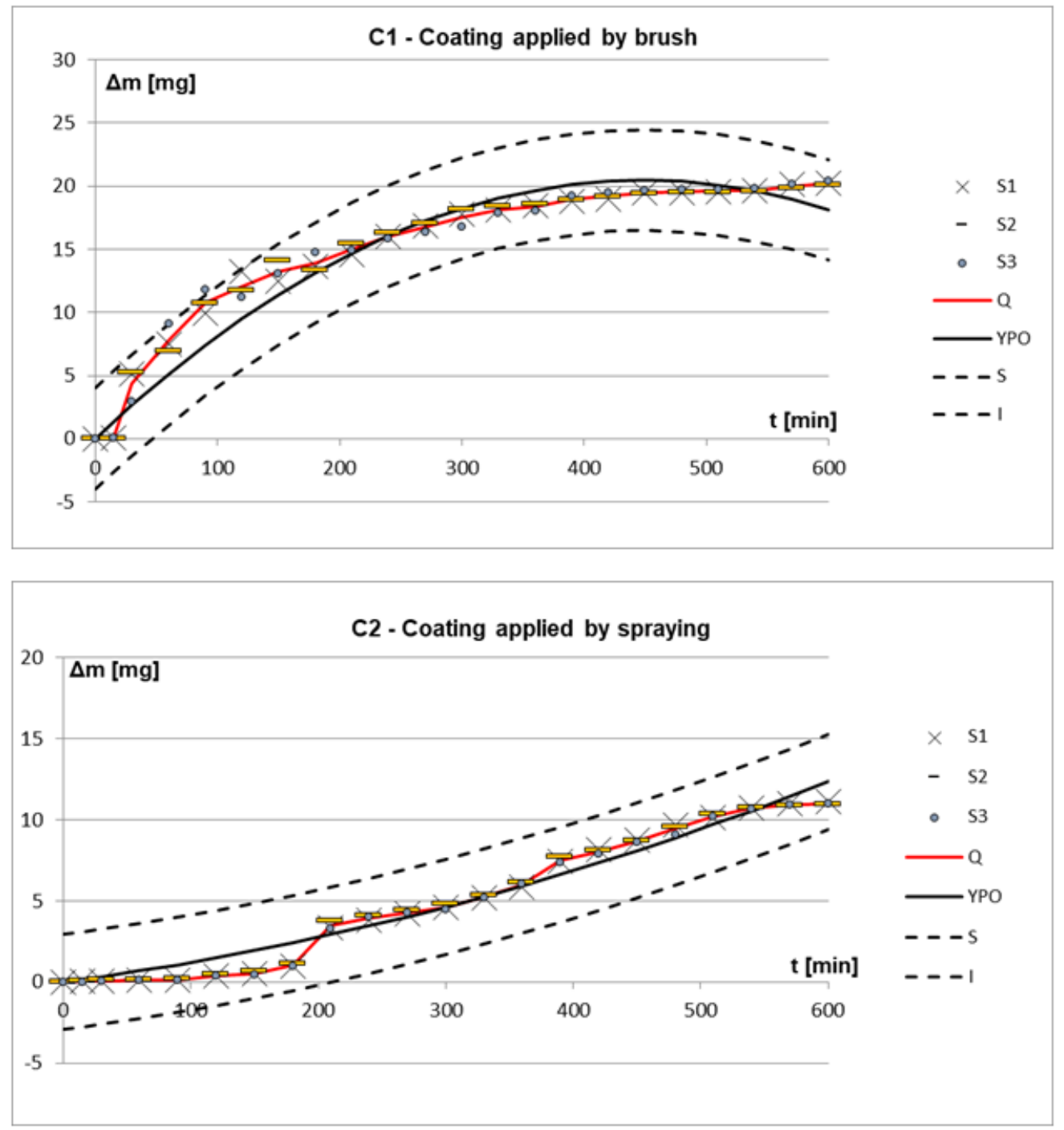

Fig. 4. The error ranges for the tested samples, where: C1-brushed coating and C2-sprayed coating; S1, S2 and S3 - the three samples tested for each type of layers; Q - the average cumulative mass loss; YPO - polynomial regression curve; S - upper range value of tolerance and I - lower range value of tolerance

As one can see, the values for both types of tested coatings fall within the error ranges specific for each layer. The maximum value of the estimated error and the average cumulative erosion value determined for all tested samples are shown in table 3. The images in figure 5 and figure 6 show the evolution of the damages caused by cavitation onto the elastomeric layers during the testing period. 

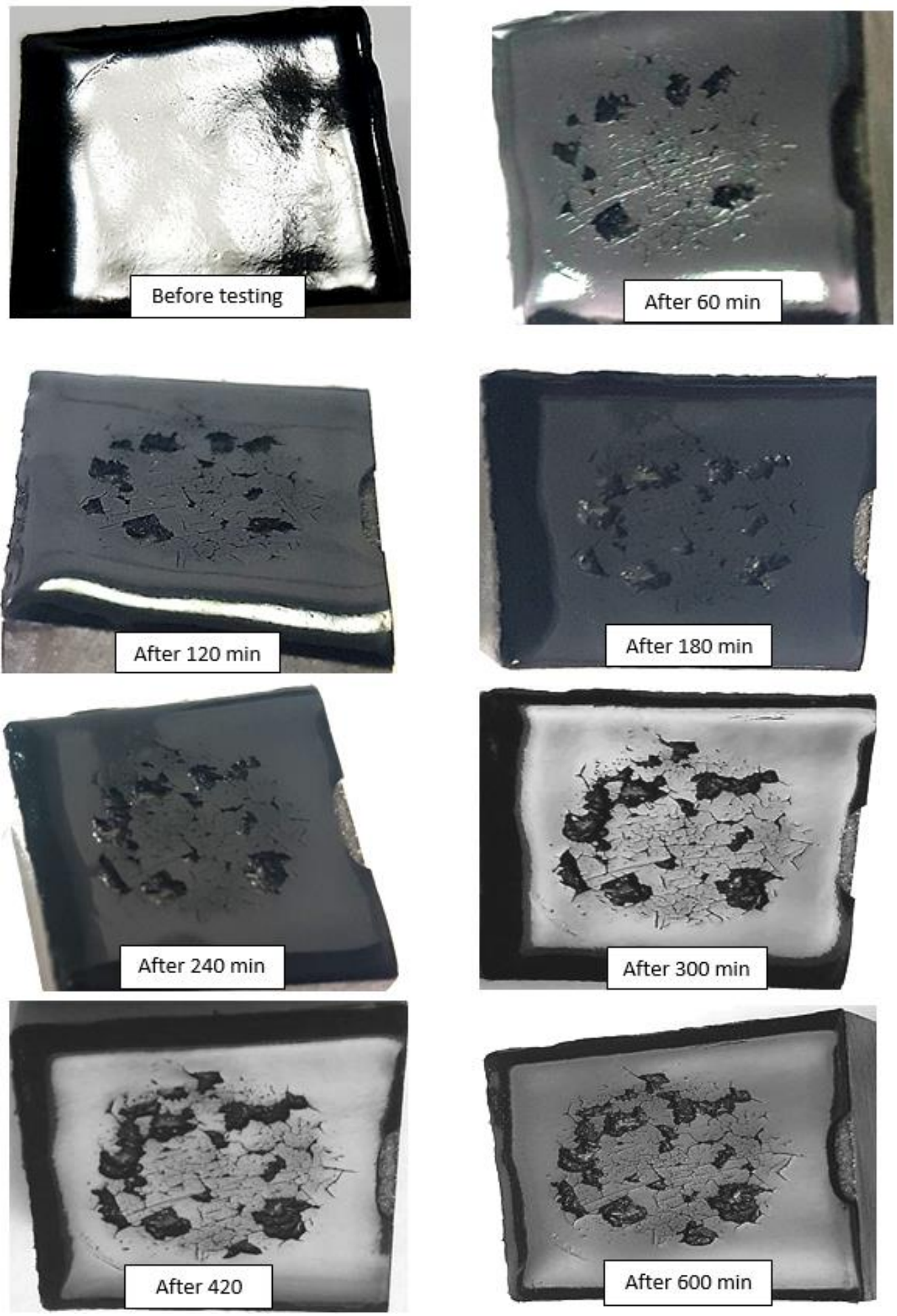

Fig. 5. C1 - elastomeric layer applied by brushing. Degradation of the surface exposed to cavitation at successive testing intervals 

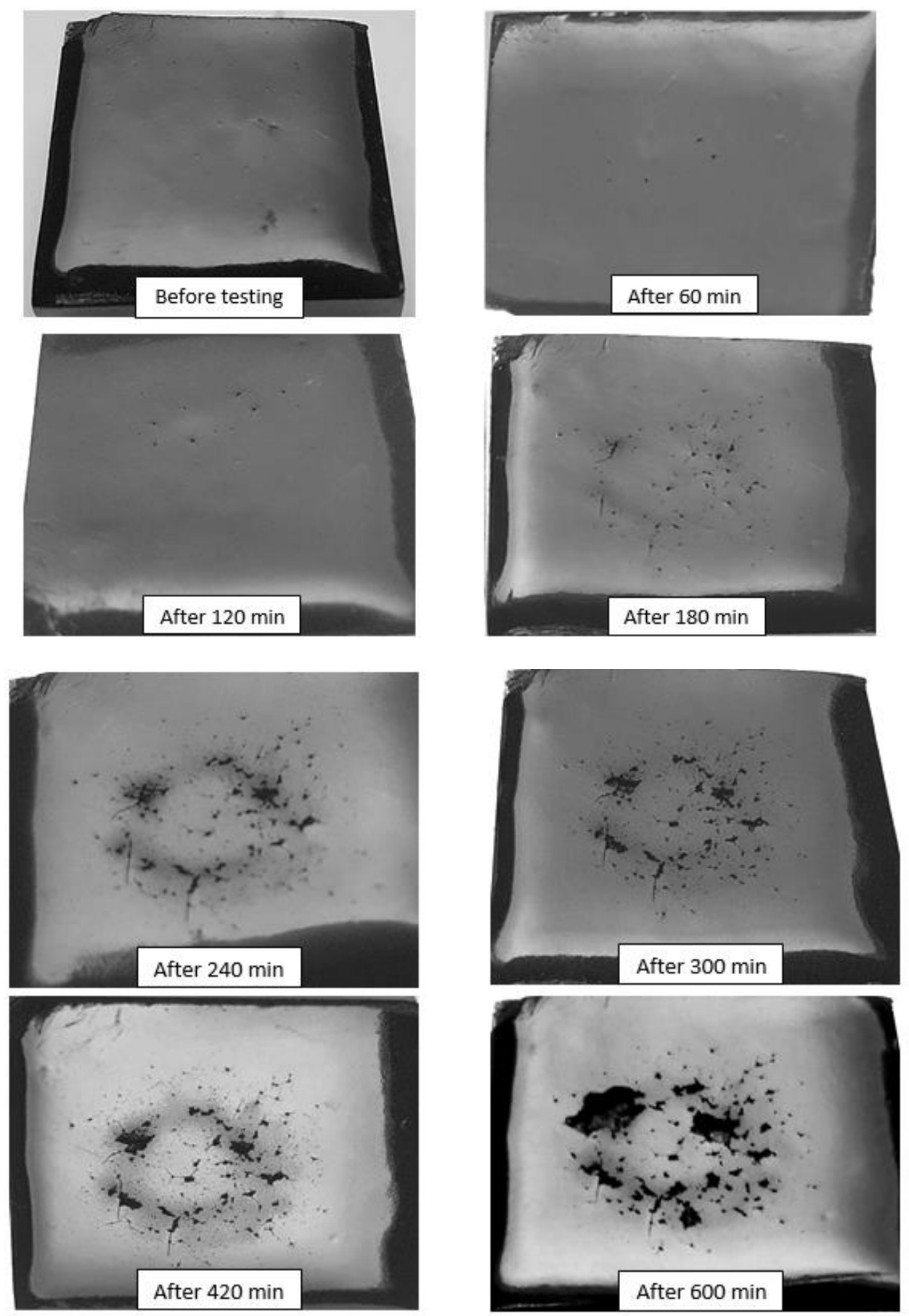

Fig. 6. C2 - elastomeric layer applied by spraying. Degradation of the surface exposed to cavitation at successive testing intervals

The macrographs in figure 5 show that the degradation process of the elastomeric layer deposited by brushing (C1) started from the first hour of exposure to cavitation and continued through the development of deep areas of surface damages interconnected by a large number of cracks. These images, associated with the experimental results represented in figure 3, confirm that the cavitation phenomenon was intensively going on during the whole testing period, conducing to the progressive material loss from the surface of the protective brushed layer.

In case of the sprayed elastomer (C2), the damage process started only after an incubation stage of about 190 minutes and the material loss during the testing period was significantly lower, as presented in figure 3 and sustained by the images of the $\mathrm{C} 2$ - specimens surface shown in figure 6 . 


\section{Conclusions}

The investigations presented in this paper are part of an extensive research program conducted by the Research Center for Hydraulics, Automation and Thermal Processes (CCHAPT) of the "Eftimie Murgu" University of Resita aiming to develop alternative repair techniques and protective coatings for cavitation affected zones on hydropower plant components.

One of the techniques evaluated as possible solution for enhanced protection against cavitation is the use of different elastomer layers, with or without reinforcements. In this paper, the authors intended to point out if the method used for obtaining elastomer coatings manifests any influence of the cavitation resistance of the protective coating. For comparison, a fluid elastomer was brushed and sprayed onto a martensitic substrate and the layers obtained were tested to cavitation resistance for 600 minutes using the vibratory indirect method.

The experimental results revealed that the deposition method influences the resistance to cavitation of the elastomer coatings. The elastomer layer applied by spaying (C2) showed significantly better resistance to cavitation than that applied by brushing $(\mathrm{C} 1)$, which is why sprayed elastomers have to be preferred.

\section{References}

1. COJOCARU V., FRUNZAVERDE D., CAMPIAN C.V., MARGINEAN G., CIUBOTARIU C. R., PITTNER A.M., EEESD, Proceed. WSEAS Inter. Conf. on Engineering Mechanics, Structures, Engineering Geology, Greece, 2010, p. 177-180;

2. EZDDIN HUTLI, ATTILA BONYÁR, DANIEL OSZETZKY, MILOS S. NEDELJKOVIC, Mechanics of Materials, 92, 2016, p. 289-298;

3. HATTORI, S., MIKAMI, N., Wear, 267, 2009, p. 2033-2038;

4. MICU, L.M., BORDEASU, I., POPOVICIU, M. O., Rev. Chim. (Bucharest), 68, no. 4, 2017, p. 894-898;

5. LEI LIU, HUALING CHENA, BO LI, JUNJIE SHENG, JUNSHI ZHANG, CHI ZHANG, YANJIE WANG, DICHEN LI, Theoretical and Applied Mechanics Letters, 5, 2015, p. 155-159;

6. VLADISLAV V. SOROKIN, BOGDAN O. SOKOLOV, GENNADY V. STEPANOV, ELENA YU. KRAMARENKO, Journal of Magnetism and Magnetic Materials, 459, 2018, p. 268-271;

7. NANYING NING, TONG MI, GUANGYU CHU, LI-QUN ZHANG, LI LIU, MING TIAN, HAI-TAO YU, YONG-LAI LU, European Polymer Journal, 102, 2018, p. 10-18;

8. SAEED SALEHI, CHINEDUM P. EZEAKACHA, GEORGE KWATIA, RAMADAN AHMED, CATALIN TEODORIU, Polymer Testing, 75, 2019, p. 48-93;

9.FRUNZAVERDE, D., CIUBOTARIU, C.R., SECOȘAN, E. R., CAMPIAN, C.V., FANICA, C., Mat. Plast., 53, no. 3, 2016, p. 557-560;

10. LU WANGA, FEI XU, YANG YANG, Engineering Analysis with Boundary Elements, 106, 2019, p. 116-125;

11. JIRI MALAC, Polymer Testing, 25, 2006, p. 650-655;

12. HAKAMI F., PRAMANIK A., BASAK A.K., RIDGWAY N., Tribology International, 135, 2019, p. 46-54;

13. KHAFIDHA M., SCHIPPER D.J., MASEN M.A, VLEUGELS N., DIERKES W.K., NOORDERMEER J.W.M., Wear, 428-429, 2019, p. 481487;

14. PETRE, I.C., POPESCU, I.N., UNGUREANU, D.N., Mat. Plast., 56, no. 1, 2019, p. 55-58;

15. CIUBOTARIU C. R., FRUNZAVERDE D., SECOSAN E. R., CAMPIAN V., NEDELONI M., Analele universitatii “Eftimie Murgu” Resita, Anul XXII, NR. 1, 2015, p. 167-174;

16.SECOSAN EVELINA ROXANA, CIUBOTARIU RELU COSTEL, COJOCARU VASILE, FRUNZAVERDE DOINA, CAMPIAN CONSTANTIN VIOREL, Advanced Materials Research, 1029, 2014, p. 146-151.

Manuscript received: 25.09 .2019 